\title{
Modern Methods of Education, Research and Design Used in Mechanical Engineering
}

\author{
Borza Sorin-Ioan, Brindasu Paul Dan and Beju Livia Dana \\ University "Lucian Blaga" of Sibiu, \\ Romania
}

\section{Introduction}

Today's society is characterized by extraordinary dynamics, information systems have revolutionized society and the pressure of change from all fields is increasingly pregnant upon individuals. More free access to information and to continuous education are the main solutions for the adaptation of individuals to social pressure. In today's complex society systems influence each other and it often happens that a discovery in a field be useful in other areas. The emergence of IT technologies is an obvious aid to education, design and research, leading to modern and efficient solutions.

In the past, the teacher was the core of classical education; conversely, today's educational actions are focused on the students, everyone's role changes and educational methods have become fundamentally different. Starting from the idea that "a man is only old once he has given up learning ", experts in education seek to provide modern learning methodologies, which can be applied irrespective of time and location.

Design and research activities employ an increasing amount of information and communication technology, which is a huge step forward. However, the importance of involving the most valuable specialists in any field has not diminished. The customers have an increasingly active role in the design and research processes now, and whereas they used to take on a much less involved stance in the pass, nowadays the entire action is directed towards them.

The Internet (abbreviation of the American expression "interconnected networks") is the distribution environment of information and a communication channel between stakeholders (tutors, students, administrators, engineers, beneficiary etc.). There is a multitude of applications, such as: email, instant messaging, discussion forums, the World Wide Web etc. that allow the exchange of information between users.

\section{E-learning}

In the technical literature, there are many definitions of the term "E-learning", all of which are associated with distance learning via the Internet.

In a broader sense, "E-learning" means "all educational situations in which ICT (Information and Communication Technology) resources are significantly used ". 
In the narrow sense, the term "E-learning" is "a type of distance education, organised by an institution that provides online materials to be assimilated by the students in their own way."

\subsection{E-learning models}

Currently, there are a number of E-learning models (Butz, 2006) developed and used worldwide in distance education. Each university, or other institution provides such programs by adopting an appropriate model - a model that it deems to be the most effective for its intended type of training.

The first model is the self-directed E-learning. This model is the simplest with respect to the number of functionalities, and is aimed at experienced learners in the process of continuous professional development, who wish to deepen specific topics. The information content consists of web pages, multimedia presentations, audio-video presentations and other materials. The content is made available to users via a hosting Web server.

The second model is called facilitated E-learning. This system combines the self-directed elearning architecture model with a range of communication facilities, such as the email or the discussion forums. Documents are often transferred through the forum, where all users have access.

The third model is the advanced E-learning, which uses advanced Web technologies for the management of the entire educational process. Such a model uses audio-video real time transmission techniques via video telephony or video conferencing applications, chat or smart boards. These facilities are added on top of the previous model. Also, the educational process follows a timetable that all the students are required to meet. Such a model is built on the LMS system (Learning Management System). The information content is covered gradually, allowing the student to deepen all aspects of a topic.

\subsubsection{Virtual university}

A Virtual University is an exclusively virtual institution that will provide specific functions for the development of educational programs (including the design of the learning materials), such as: tutorials and guidance, production, storage and distributing of educational materials, management and accounting (financial problems), marketing, evaluation and accreditation.

Conventional education systems often attempt to create secondary distance learning programmes, however their administrative structures are often incompatible or poorly adaptable to these. Also, traditional institutions are usually sceptical towards distance education, deeming it unable to achieve satisfactory results. Therefore, they are reluctant in invest in this direction.

A virtual university, on the other hand, can be fully devoted to this educational model, therefore being more likely to meet the requirements of distance learning students.

\subsubsection{Trends in E-learning system development}

The most significant context in which E-learning technology is used is distance education. Used primarily as an education tool for remote locations, especially in Australia, this system became widespread as a result of the development of communication technologies and the 
rise of the Internet. Distance education is just an expression of the new trend for the consumers of the various training institutions. The accumulation and transfer of credits as well as the modularisation of courses are parts of the same structural transformation of the educational system.

Widespread acceptance of the various types of distance education and training, from study by correspondence to E-learning, is far from complete. The inclusion of distance courses in the common practice of training will have be preceded by multiple efforts of raising the quality standards, supported by research in the field.

\subsection{The E-learning architecture}

Increasing pressure faced by organizations (universities included) compel them to be organized in a better performing manner. High flexibility is another requirement, so as to enable them to quickly implement continuous improvement processes. A few reference architectures were created in order to assist the organizations in this work. They provide frameworks (templates) for certain fields. These templates typically consist of a list of modules, domains and specific functions and interactions between them. They also contain elements and features located outside the studied architecture.

Figure 1 shows an example of a reference architecture specific to E-learning educational systems. The product life cycle stages (of system development and use) specific to Elearning system are presented on an axis and the main entities and actors interacting with it, on the other. At the intersection points of these modules the main activities that characterize an E learning system are described.

We will further dwell upon certain issues that were outlined in the framework of investigations conducted at the Faculty of Engineering of Sibiu (Romania) in the Industrial Engineering team, as they have completed the construction of a learning system in the cutting mechanical processing and cutting tools. The most interesting aspects are the development of an on-line course and the issuing of the tutorials.

\subsection{Development of an on-line course}

The devising of an E-learning course requires a greater effort than in the case of its classic counterpart. This is because the system is lacking the possibility of direct human interaction and thusly requires a well set up series of images, animations, questions and evaluations to compensate for this.

\subsubsection{Design stages of an on-line course}

Designing a course goes through a set of predefined steps, as showcased below:

1. Identifying the strategic role of the new product, which should be reflected in the strategic plan of the faculty and in the curriculum. It is important to settle upon the type of the course (new or improved), its objectives, the required knowledge, the specific skills that will get at the completion of the course etc;

2. Generating the "idea", with the application of methods and techniques (including creative ones), in order to complete the new course. The teaching strategy includes: type learning 
(individual or in groups), the possibility of presenting movies and animations, access to some web pages, tutorials, availability of interactive materials, bibliographical research and classification of information, application activities and design, support offered by the teacher in the event that the pupil encounters obstacles etc.

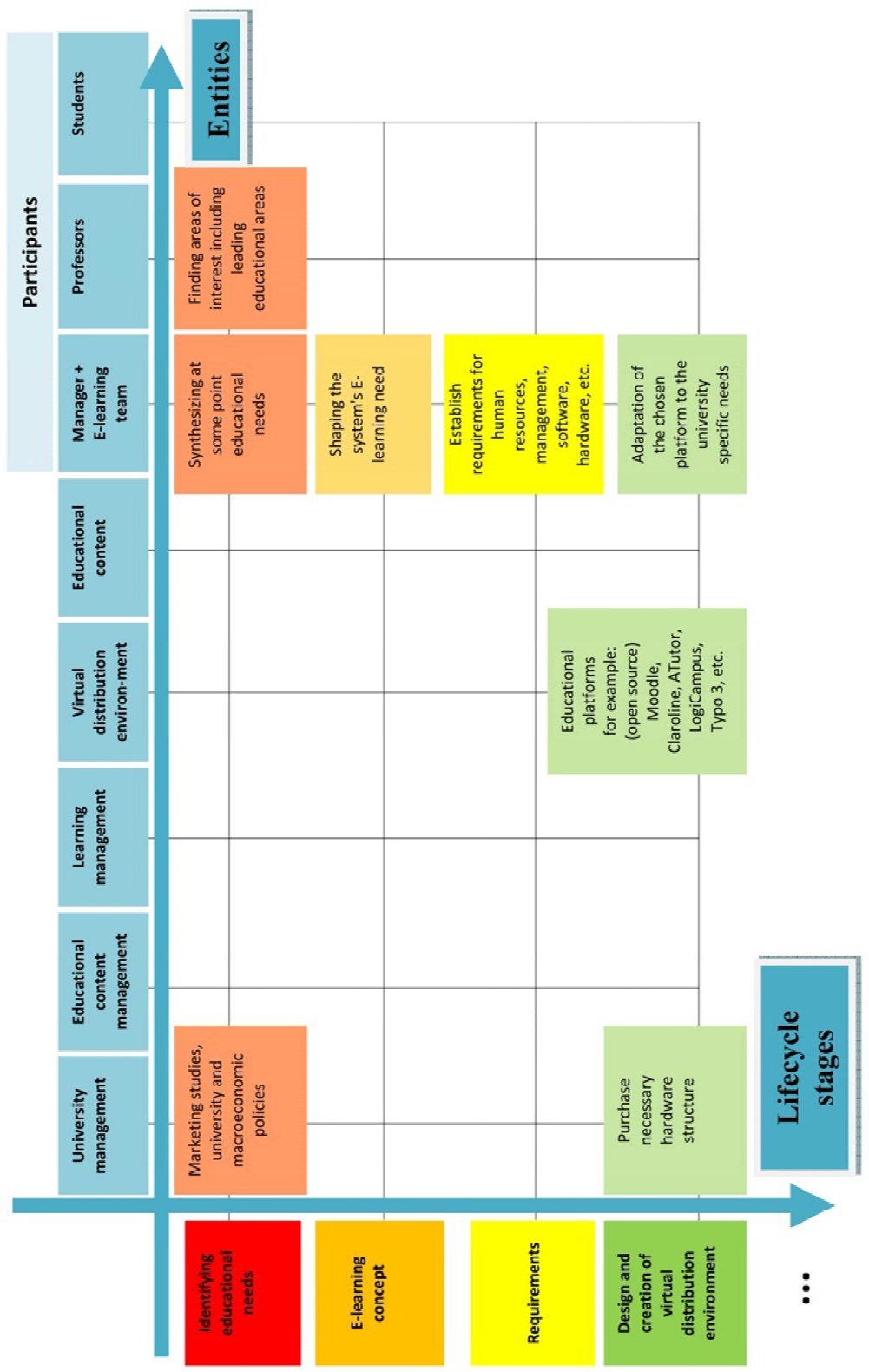

Fig. 1a. E-learning architecture 


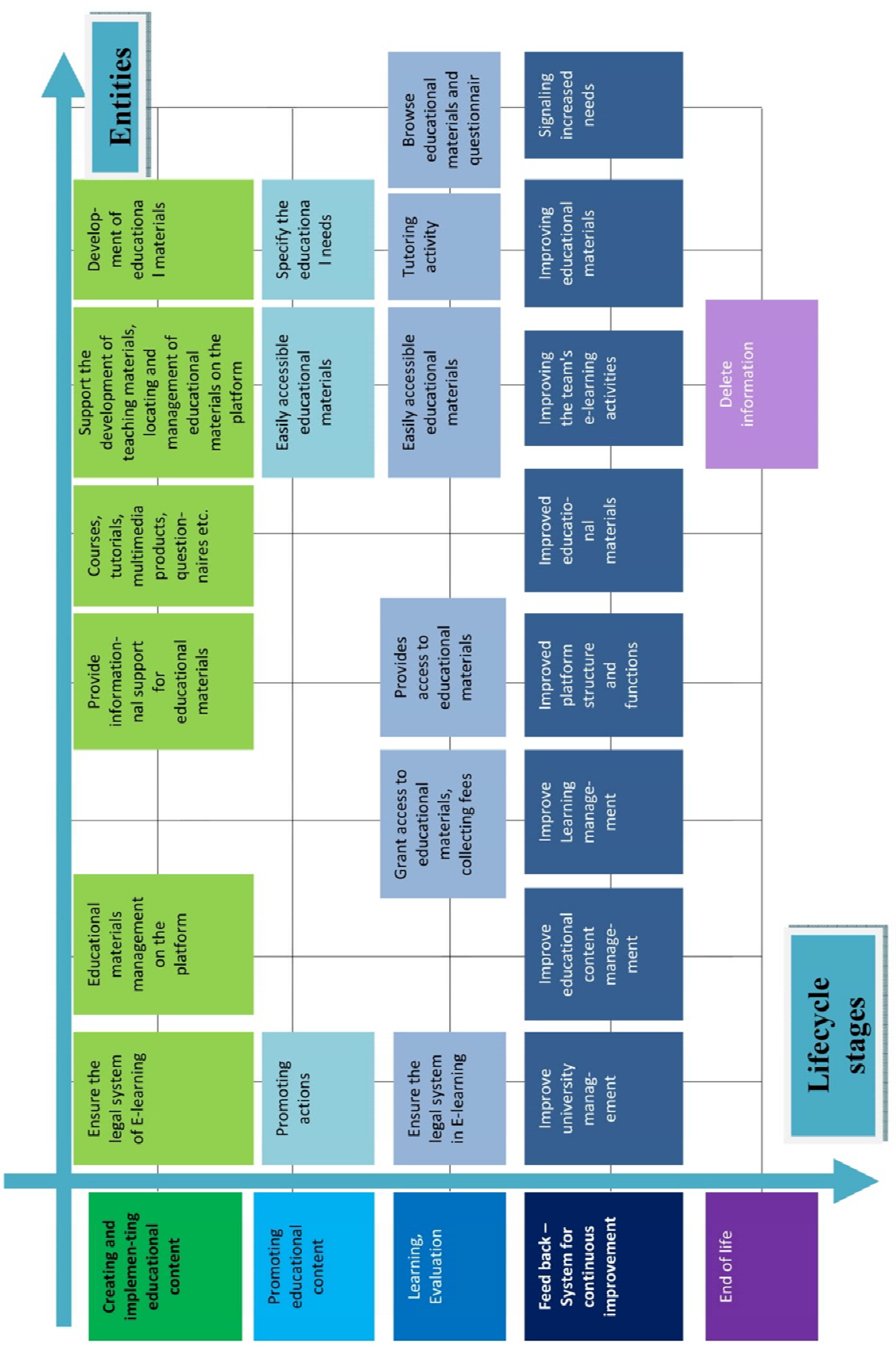

Fig. 1b. E-learning architecture 
3. The positioning of the new course to the other offered courses (topic, audience and importance within the program) to predict the cost of implementation, efficiency and monitoring;

4. Completion and testing of the first versions of the course, including the ability to do the new course by the faculty team;

5. The economic analysis, identifying the economic potential of the new product, including effectiveness in learning, for students;

6. Developing and testing the new course based on specific methods and techniques, which results in a report of the chosen solution and a definition of its essential characteristics;

7. Market testing, which validates the proposed strategies and corrects errors done in the preview stage;

8. Promotion of the new product;

9. Launch of the course within the study program, which comprises its implementation and validation of the accuracy of the results obtained in the earlier stages of the "product" development (reality test).

\subsubsection{Example development of an E-learning course}

As an example, we will go into further detail upon an E-learning course in the area of cutting tools.

Its main aspects are:

- The objectives:

- development of creative thinking applied to the field of cutting tools;

- $\quad$ knowledge of the role of cutting tools in the technological system;

- gaining an understanding of the design and manufacturing principles of cutting tools;

- ability to make the right choice of tools for different machining operations;

- identification of the key issues in the manufacturing and management of modern cutting tools;

- getting users familiar with the software for constructive and technological design of the cutting tools;

- $\quad$ creative design via the internet.

- The previous knowledge necessary for browsing this course encompasses:

- the geometry of the elementary tools;

- the parameters of cutting tools and the optimal choice for these parameters ;

- $\quad$ surface generation;

- cutting phenomena: chip formation, cutting forces, cutting tool wear, surface quality etc.

- The specific skills that will be gained at the completion of the course:

- knowledge and understanding: Students will learn the role of cutting tools in the technological system; they will grasp the principles of construction and design of the cutting tools; they will know how to choose tools for various machining operations;

- explanation and interpretation: the attaining of the technical general principles in the cutting tools area and ability to implement them; the discovery of known constructive solutions (tools), as well as the ability to develop new solutions by customizing generalized models; 
- $\quad$ applied skill: students will identify key issues in the operation and management of modern cutting tools; they will work with software for constructive and technological design of cutting tools; they will attain an appropriate command of the technical language;

- attitude: the ability and habit of using modern means of documentation and communication; internet use, etc.

The application was focused on teaching the students creative design of cutting tools by using the Internet, and therefore the material lacks some specific elements (access to other web pages, specialty movies, group activities, work on the forum, etc.).

In figure 2 the main page of the cutting tool platform can be seen

(http://edesign.ulbsibiu.ro/moodle/).

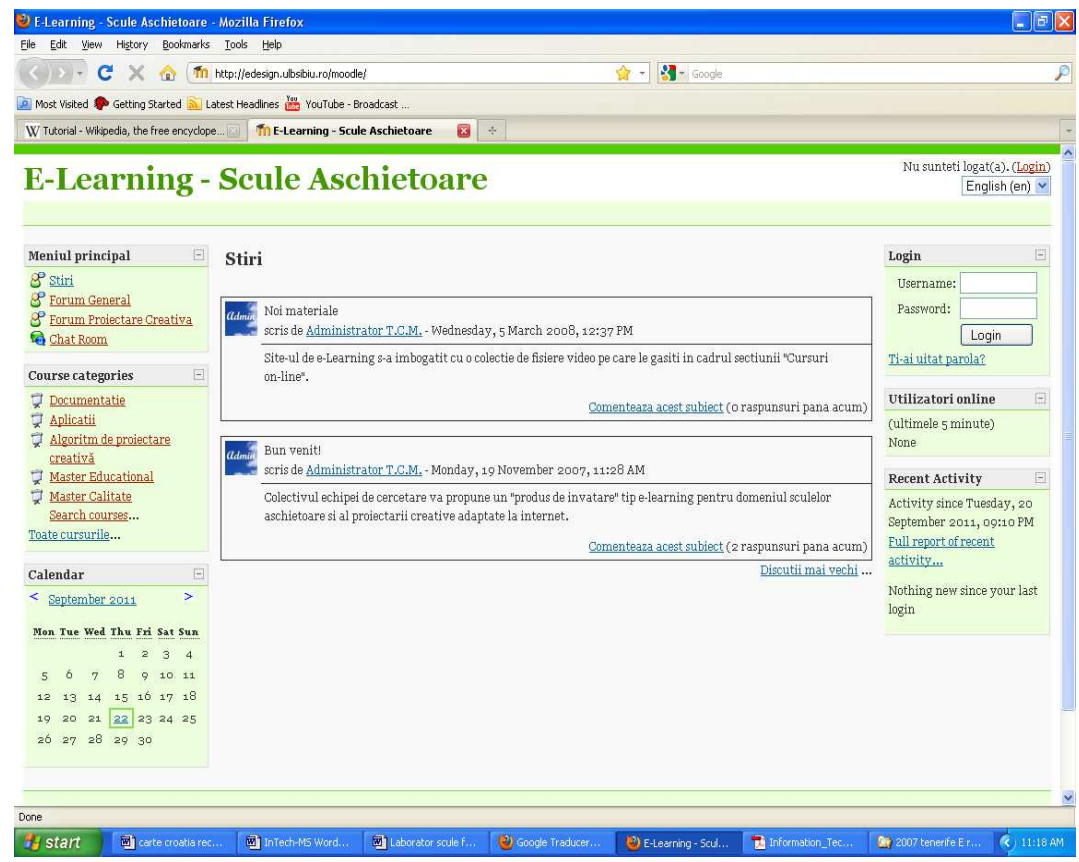

Fig. 2. Main page of cutting tool platform

The beneficiaries of such a training, are students who have a "Cutting Tools" discipline in their curriculum (Manufacturing Engineering program), as well as users from companies, who want advanced constructive solutions for cutting tools used in manufacturing processes and who co-opt specialists from several locations (consulting centres, designers, cutting tool providers, teachers, etc.).

The teaching strategy of the course is described in a written presentation of general "information packages", but also by modules (depending on the type of cutting tools), with drawings, images, animations and movies that explain the construction, the functioning, as well as further subtleties of the cutting process. In addition, references are made to various sites of the major cutting tool companies. 
Afterwards, design algorithms are presented for different types of tools as well as separately, methods and creative design techniques.

An objective of the proposed on-line course is, as it has been pointed out, the comprehension of the creative design, on the Internet. Therefore, at the beginning, the designing of algorithms for each type of cutting tool is presented. This makes it possible to achieve the level of knowledge required in this area. The next steps are the study of creative techniques adapted to the Internet, ways of working in groups and, finally, team design, visualisation, on-line building of prototypes etc.

Regarding the assessment (for the presented case), complex online tests are used and gradually developed. After the bibliography and the specific materials (course) are completed and after reaching a certain level of competence, the E-learning system allows the formation of working groups with the participation of a professor, in order to design cutting tools using the Internet (e.g. on the forum).

The testing method provides a good balance between the objectives, their qualities and the time required for development. It also provides a high level of objectivity and repeatability.

A test sample used in the chapter on turning tools is given below, where knowledge is gradually targeted. The students identify at first the principles of operation and the construction of various parts of the turning tools. Only afterwards does he discover the constructive solution.

In order to develop complex tests with powerful imagery, the "Quizmaker" software was used. The program provides twenty kinds of questions with which tests can be built. These include dual-choice items, completion items, multiple choice items, etc. A picture, sound or video can be added to each question. Also, the score may vary from one question to another, and the percentage required for promotion may be changed. The default is $70 \%$.

It is impossible to skip a question without giving an answer. It is possible to limit the time for each question or for the entire test.

You can choose to complete the test multiple times (as allowed by the creators of the test), and every time you start the answers will come in a different order. At the end of the test, the student can get a message informing him or her if he has passed. In the end he or she can see the correct and incorrect answers and print the results.

An example is presented next.

Choose the insert, the tool body and the clamping system in order to build a turning tool with changeable insert:
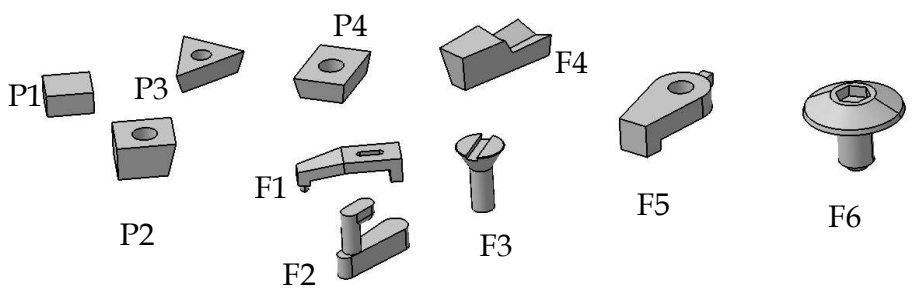

F6 

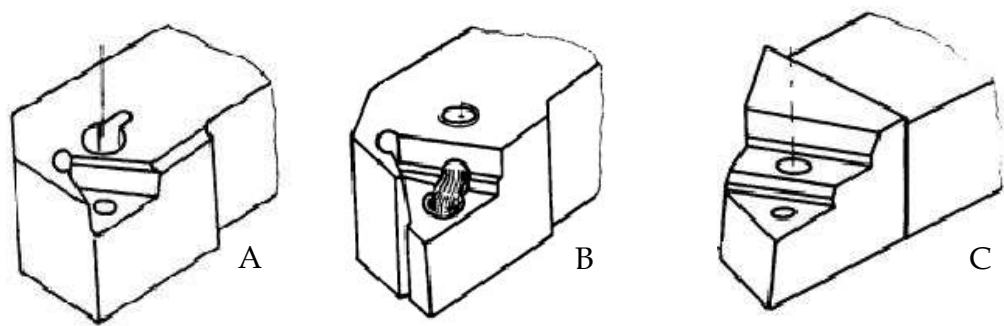

\begin{tabular}{|l|l|l|l|}
\hline & Tool body & Insert & Clamping system \\
\hline Turning tool & & & \\
\hline
\end{tabular}

The field of cutting tools is extremely dynamic and therefore continuous improvement is very important.

In our example, at some point the professors involved added a number of new features to the product: animations, videos and a streaming facility, through which users can observe the activity of the CNC Realmeca-Compa-ULBS Laboratory and of the Smart Factory Laboratory of the Faculty of Engineering (ULBS) remotely.

In order for the supervisors of the project to receive feedback, the students respond to a number questionnaires about the activity that they have performed, about the quality of the programme, about the the collection and analysis of tests etc.

\subsection{Tutorials}

The notion of a tutorial emerged together with the development of IT technologies.

The tutorial is a tool often used nowadays in various fields in order to present a specific software product or business activities-products of a given company, etc. In making a tutorial there are several concepts to be taken into account, such as:

- Entrain Multimedia presentations in business and education;

- Enlight concept of dynamic templates for online communication;

- Enlife web concept training and E-learning

The user has the option of creating material-support improving message and audience impact. Tutorials are used in different situations:

- $\quad$ as an auxiliary tool for university courses or other teaching activities;

- for supporting communication in scientific sessions, symposia, workshops, etc.;

- for communication between employees at the level of economic organizations;

- for communication between economic organizations, in the vendor-client relationship;

- for the dissemination of information via public computers (electronic information systems, electronic kiosks, info-kiosks);

- for development of tutorial-based applications, in closed systems, mixed or open (in the Internet environment).

The presentations are integrated with the Office software systems, being aligned with the principles of interaction and with the available instruments. They are geared towards solving the problems of communication and ensuring the possibility of personalization by 
including elements of interactivity with the receiver user. The development of several versions for each application leads to the diversification of methods, which range from a simple slideshow to rich multimedia applications.

The tutorial aims to introduce participants to the educational process in a given subject, with the final goal of assimilating a minimum level of knowledge. But there are some fundamental differences from other educational processes:

Educational methodology is rich in media content (static content, motion screenshots, animation or video instructions), which is necessary in order to exemplify the necessary steps in solving the problem.

- There is a focus on a particular topic, without details about adjacent concepts.

- A tutorial cannot replace a course, so theoretical aspects are usually overlooked in favour of practical ones. Theory is only mentioned when it becomes absolutely necessary to explain an applied situation.

- In general, if software is permanently installed, the tutorial makes reference to the way of using multimedia software;

- A minimum of IT resources and documentation (for the hardware, the software and the prerequisite knowledge), time and motivation are the only things necessary to acquire a tutorial.

\subsubsection{The steps involved in making a tutorial}

Usually the tutorial starts with an introductory section that informs the student about the objectives and the nature of the lesson (Borza et al., 2007). The information is then presented in a determined form. Questions that are addressed to the student receive an answer. The program considers the student's response and provides a reaction in order to strengthen the understanding and to increase student performance.

The constituent parts of the tutorial are:

- Introduction;

- Monitoring of the student on browsing the lesson;

- Motivating the student;

- Presentation of the information;

- Questions and answers;

- Answer analysis;

- Additional guidance depending on the accuracy of the responses;

- Sequencing/Segmentation of the lesson;

- Completion of the tutorial.

Usually there are several steps to be followed when creating a tutorial:

1. establishment of the subject that will be treated in the tutorial;

2. determining the target audience who should attend the tutorial. The difficulty level, as well as the estimated time of browsing must be determined. These two affect the degree of motivation for learning. It is preferable to have a short tutorial that covers a more limited topic, instead a richer one that demands for a lot more effort. 
3. choice of the type of technology to be used. The elaboration of a tutorial that explains a software application requires complex IT elements.

4. compiling, structuring and placing information in the tutorial;

5. tutorial test, and correction of any conceptual and/or implementation mistakes that may arise

\subsubsection{Multimedia}

Multimedia is everything you can hear or see: texts, books, pictures, music, sounds, CDs, videos, DVDs, Records, Films, and more. Multimedia comes in many different formats. On the Internet you will find many of these elements embedded in web pages, and today's web browsers have support for a number of multimedia formats. The support for sounds, animations and videos is handled in different ways by different browsers. Some elements can be handled inline, some requires a plug-in and some requires an Active control. Multimedia elements (like sounds or videos) are stored in media files. The most common way to discover the media type is to look at the file extension. When a browser sees the file extensions .htm or .html, it will assume that the file is an HTML page. The .xml extension indicates an XML file and the .css extension indicates a style sheet.

Picture formats are recognized by extensions like .gif and .jpg. Multimedia elements also have their own file formats with different extensions.

\subsubsection{Multimedia sound formats}

The WAVE (waveform) format is developed by IBM and Microsoft. It is supported by all computers running Windows, and by all the most popular web browsers. Sounds stored in the WAVE format have the extension .wav.

MP3 files are actually MPEG files. But the MPEG format was originally developed for video by the Moving Pictures Experts Group. We can say that MP3 files are the sound part of the MPEG video format. MP3 is one of the most popular sound formats for music recording. The MP3 encoding system combines good compression (small files) with high quality. Expect all your future software systems to support it. Sounds stored in the MP3 format have the extension .mp3, or .mpga (for MPG Audio). The AIFF (Audio Interchange File Format) was developed by Apple. AIFF files are not cross-platform and the format is not supported by all web browsers. Sounds stored in the AIFF format have the extension .aif or .aiff.

\subsubsection{Multimedia video formats}

The AVI (Audio Video Interleave) format was developed by Microsoft. The AVI format is supported by all computers running Windows, and by all the most popular web browsers. It is a very common format on the Internet, but not always possible to play on non-Windows computers. Videos stored in the AVI format have the extension .avi.

Microsoft develops the Windows Media format. Windows Media is a common format on the Internet, but Windows Media movies cannot be played on non-Windows computer without an extra (free) component installed. Some later Windows Media movies cannot play at all on non-Windows computers because no player is available. Videos stored in the Windows Media format have the extension .wmv. 
The MPEG (Moving Pictures Expert Group) format is the most popular format on the Internet. It is cross-platform, and supported by all the most popular web browsers. Videos stored in the MPEG format have the extension .mpg or .mpeg.

Apple develops the QuickTime format. QuickTime is a common format on the Internet, but QuickTime movies cannot be played on a Windows computer without an extra (free) component installed. Videos stored in the QuickTime format have the extension .mov.

To achieve multimedia tutorials one can use both Internet and INTRANET technologies based on what was mentioned above. This depends the type of software used. For image processing, one can use software like: Photoshop, Corel Draw, or open source products, like GIMP. To achieve animation we can use the FLASH product or software that captures the screen image like Camtasia. We will write some words about Camtasia in the "Video Tutorials" section of this paper.

\subsubsection{Streaming applications}

The increase of the accessibility of video equipment has allowed the development of online educational resources. Making interactive distance has now become possible by following a multimedia technology developed recently, namely streaming technology.

Streaming data is transmitted in the form of streams, which refers to the ability of an application to play synchronized media data streams in a continuous manner, while those streams are transmitted to the client through a data network. Streamed data is divided into packets whose size is suitable for transmission from one server to the client. Thusly, a user can view a package, while at the same time receiving and uncompressing the following parts. The great advantage here is that they don't have to wait for the end of the transmission in order to view the material.

Applications that can be built using streaming services are viewed in figure 3 and divided into:

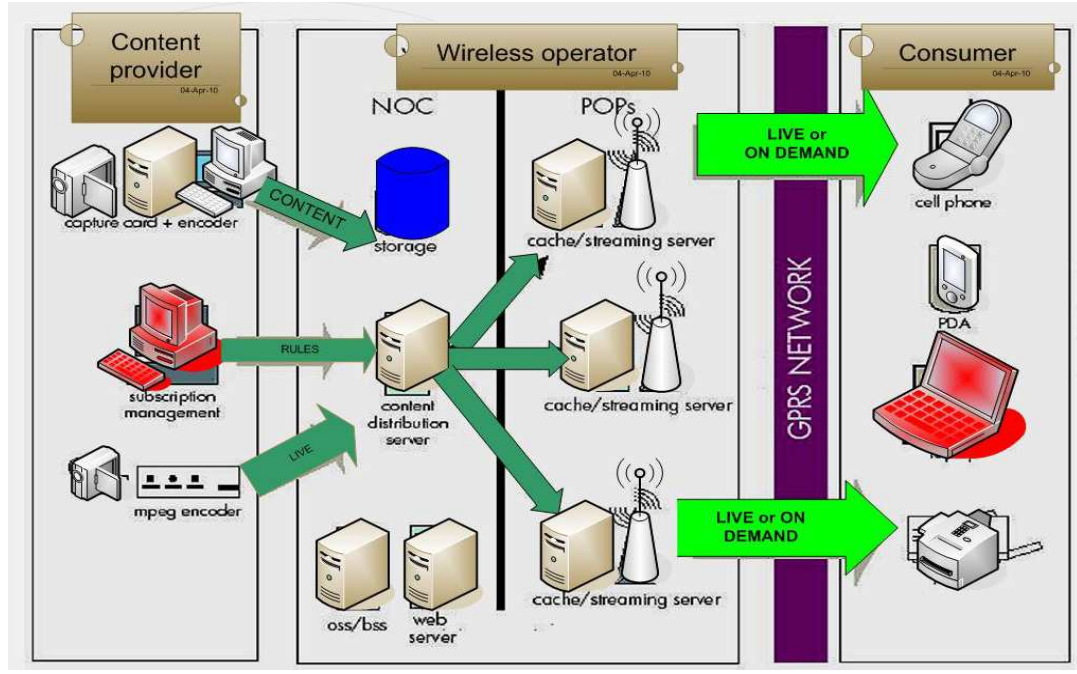

Fig. 3. Streaming Applications 
- $\quad$ on demand applications - news, music, movies, multimedia tutorials;

- $\quad$ live information - radio and TV programs directly.

On-demand streaming is based on files stored on a server for a longer period. Files are available to customers as they submit their requests to the server. Live streaming videos are transmissions that occur as the performances or events depicted take place. Streaming technology has caused a profound change in education, business, media and entertainment, as it combines the richness of television content with the interactivity of the Internet.

\subsubsection{Video tutorial in engineering educational process}

Video tutorials are not a new concept. The concept has emerged in the late 1960s, when Bandura, first commented on the issue of self-modelling. Since then, video modelling has been described as "instructional videos" or "video tutorials". Most video tutorials are produced as part of a strategy to promote guidance in developing new skills and abilities for example, to improve teacher training or to prepare medical students for their internship experience. Also, video tutorials have been used to assess their effectiveness in improving the learning efficacy of students.

Video tutorials are one of the most important factors in the improvement of the educational process. As we also mentioned in the conclusions of this work, the video tutorial has a strong impact on students. It can exist in two modes. The first one is as a separate entity with no text. In this case several independent tutorials treat a particular topic. The second mode is having it embedded in a website, or as part of a topic that is presented in the context of web page or slideshow. In both cases the video tutorial is recorded using specialized software.

By offering audio-visual demonstrations, the teacher can use a video tutorial to develop a particular skill or strategy. Thus, video tutorials can be used as a medium to encourage students to learn independently outside the regular classroom schedule. The materials presented in the audio explanations and the visual demonstrations become achievable goals that the learner can reach by understanding and applying a similar process to produce their own project. The video tutorial resources may used to engage learners to explore their technical skills. Exposure to software operation in the target language might empower students to become familiar with the target technical lexical items thus enabling them to discuss their difficulties with their teacher or peer. Hence, the teachers' role becomes one of facilitator or guide when a student needs further assistance, and their oral interaction has the potential to change from language learning to purposeful communication exchange whereby problem-solving is the focus.

\subsubsection{Making video tutorials using the Camtasia software}

Camtasia is one of the applications that can be used to make a video tutorial. TechSmith produces it. Video tutorials created with Camtasia assists in creating demonstration videos by recording computer screen activities. For example, one could video record the screen as they type. Even though Camtasia is fairly user friendly, some video editing skills are necessary. 
After recording the screen activity, Camtasia stores the recording on its editing environment. During the editing stage it is possible to add narration, music, photos or other movie elements. Finally the finished video tutorial can be saved - either on a CD or DVD, or, it can be uploaded on a website for online access.

\subsubsection{Example of a video tutorial for learning the $G$ language used in mechanical engineering}

To ease the study of the programming language $G$, an on-line tutorial has been designed, which uses multimedia elements to provide examples for the main notions involved. The tutorial contains 17 lessons (fig. 4.), which are titled as follows: About Labview, Windows,

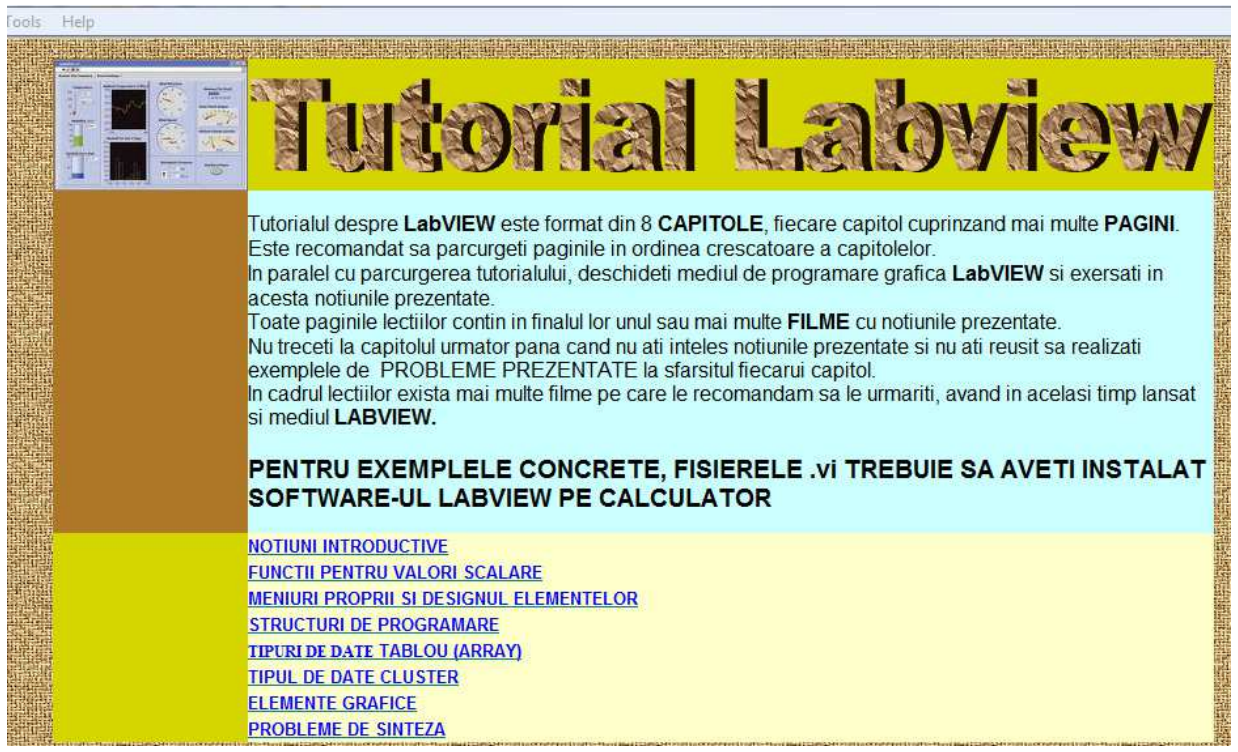

Fig. 4. The Home page of G Language Tutorial

Build VI, Data Type, SubVI, Debug, While Loop, For Loop, Array, Clusters, Case Structure, Sequence structure, String, Files, Build an Application. Each lesson contains text and pictures, in which the content is illustrated. The tutorial begins with an introduction that provides some initial background (figure 5.). "LabVIEW is a tool by National Instruments Company. It is an integrated development environment (with graphic interface), based on the $\mathrm{G}$ language. It is different from other development environments in that programming in LabVIEW is based on the concept of connecting icons.

When using LabVIEW there is no need to write any source code, it is enough to create a graphic representation of the desired program, using icons. Connected icons make up diagrams representing the data flow from the data sources to the program output. The inputs and outputs can be either external devices or user interfaces (on a diagram they are represented by an appropriate icon). This unified interface between LabVIEW and external devices makes it easy to set up the computer as a supervising and controlling device. LabVIEW is often used in research centres". 


\section{E-design, E-research}

\subsection{E-design, E-creative design a redefined notion}

A definition of the notion of "E-design" could be "the design process that occurs on the Internet with the help of the computer". The E-design concept is starting to be better known and used, even though for the moment it is only more prominent in the design and consultation sites in the field of arts and architecture. E-technological equipment in the design is still in its infancy.

By applying creative methods in the aforementioned processes, one can achieve a more advanced e-design, namely E-creative design (Brîndasu \& Beju, 2007).

This notion has appeared in the technical literature, but under a different meaning - the meaning of an original and effective platform. The team from Sibiu, however, considers that this term, namely E-creative design, is a superior stage of the Internet design for using creative methods specific to group activities.

Some benefits derived from implementation of an E-creative design in technological equipment are (Creswell, 2009):

- A decrease in design time;

- An increase in the degree of innovation (e.g. cutting tools);

- Use of the capacity of the most valuable resource (human, material) in the project;

- Generation of new tools, technologies and networks for specific applications;

- An ensuring of the compatibility requirements for the integration in the social / economic Europe.

The adaptation of the methods and techniques of creative design for the network involves the establishment of working procedures, the enabling of the design (e.g. Cutting tools) in an innovative way, as soon as possible. That should, however, not hinder the work of the designer (expert), but rather it should facilitate and enable the participation of the consumer, even to the process itself.

\subsection{E-research}

The concept of E-research refers to research that is carried out in virtual teams, using the Internet, and to which the participants lie in various locations.

The research methodology prescribes the following steps:

- description of the problem. This must be performed as clearly as possible, as it determines the type of research to be carried out.

- $\quad$ research planning using project management methodology;

- tracking of the actual conduct of research;

- design and implementation of a prototype;

- experiments on the prototype;

- final analysis - interpretation and dissemination of the results;

- audit of the project;

- lessons for the "use" and shipment the product to the customer. 


\subsection{Trends in design-research centres}

The trend in terms of research and design centres is international cooperation and collaboration. These can be achieved by organizing virtual research and design centres.

The development of communications and computer technologies (ICT) offers the possibility of using the Internet in research design activities (E-design E-research), within virtual centres (Kincheloe, 2006).

Virtual research combines a variety of activities, as follows:

- Information retrieval is eased by the search capabilities of the platform;

- Identification of the general objectives should only be made by taking into account the world trends;

- Whenever goals are set for shorter terms, their planning can be achieved with better accuracy;

- The organization of resources is much more efficient due to the wider access to human resources. Physical attendance is unnecessary, user on-line connectivity is sufficient;

- The realization phase in the virtual research centres is performed much faster due to greater information transfer speed;

- The research results can better meet the initial needs because of on-line prototyping. Whenever the prototype development indicates a deviation from the proposed objectives, corrective action can be undertaken.

- Virtual events can take place in the virtual centre, in a chat room, or a forum;

- Advice can be provided via email, chat;

- Cooperation in solving problems or discussions in the study group can be achieved through the forum or chat, virtual communities, international scientific collaboration via Web/Internet;

- The system allows shared editing of documents.

The major objective of the future research/design centres has to be the improvement in the performance of the centre for international exchange of knowledge.

Future research-design centres can be viewed as appropriate mechanisms to establish links with world research, as well as to prevent the need for researchers to work "behind the walls". This could be a solution to stop the migration of researchers in countries who have a much higher technological development of information and communication.

A proposal for organizing a research-design activity within the virtual research-design centres was put forward in the domain of mechanical engineering and, more specifically, in the field of cutting tools, by using the E-creative design concept.

\subsection{E-research - E-design methodology}

Because the research activities are carried out in teams and because researchers are located in different places, there is a clear need for a precise methodology for communication research. These are supported by the TEAM CENTER software.

The stages of a research methodology are:

- clear description of the problem; 
- determining the type of research that needs to be done;

- planning of the research, using the methodology of "Project Management";

- research activity and tracking;

- $\quad$ the design and manufacturing of a prototype (if necessary);

- experiments and analysis of the final product;

- the interpretation and dissemination of results;

- completion of the audit of the project and raising awareness upon the "lessons" to be learned;

- $\quad$ research delivery to the beneficiary.

The Industrial Engineering department from „Lucian Blaga” University of Sibiu did a research design platform focused on creativity. The main theoretical and practical issues of the research activity performed on this platform are presented below. For an easier understanding, an example was used.

\subsubsection{Problem definition}

In management and engineering, a problem can be defined as the difference between the real and the desired situation. In general, the real causes are not known and a careful analysis of the root causes is needed in order to determine the true nature of the problem. Correct and complete understanding of the issue is very important and necessary in every situation, especially in the situation of a collaborative network, in which participants exchange information in synchronous or asynchronous mode. The problem needs to be explained in a textual and/or graphical way and afterwards communicated over the network.

The main steps that must be followed in order to define a problem in the communication network are as follows:

- the formation of a virtual team for defining the problem;

- individual studies or E-sessions, performed in order to determine the fields (e.g. technical, managerial, economical, ecological, legal, etc.) and in order to identify key indicators, parameters or behaviours. Additionally potential feedback loops caused by different parameters, contradictions, as well as other risks and uncertainties have to be acknowledged;

- E-sessions, in order to determine the problem, as well as research and design topics.

In order to communicate information in network in the best possible manner, it is very effective to use the methods of the "root cause analysis". These methods are as follows: 5Whys, Ishikawa diagrams, failure mode and effects analysis, fault tree analysis, Pareto analysis, inference, TRIZ methodology etc.

In order to perform a correct and complete definition of the problem, it is useful to organize several E-session with that purpose.

The theme of the provided example was, as shown in figure 5, the designing of a boring head. This boring head was required to process at several diameters, as well as to create a chamfer at the end of the hole (that the chamfer tool could cut different dimensions depending on the boring head diameter). The material to be processed had "high" features and the manufacturing series was small. 


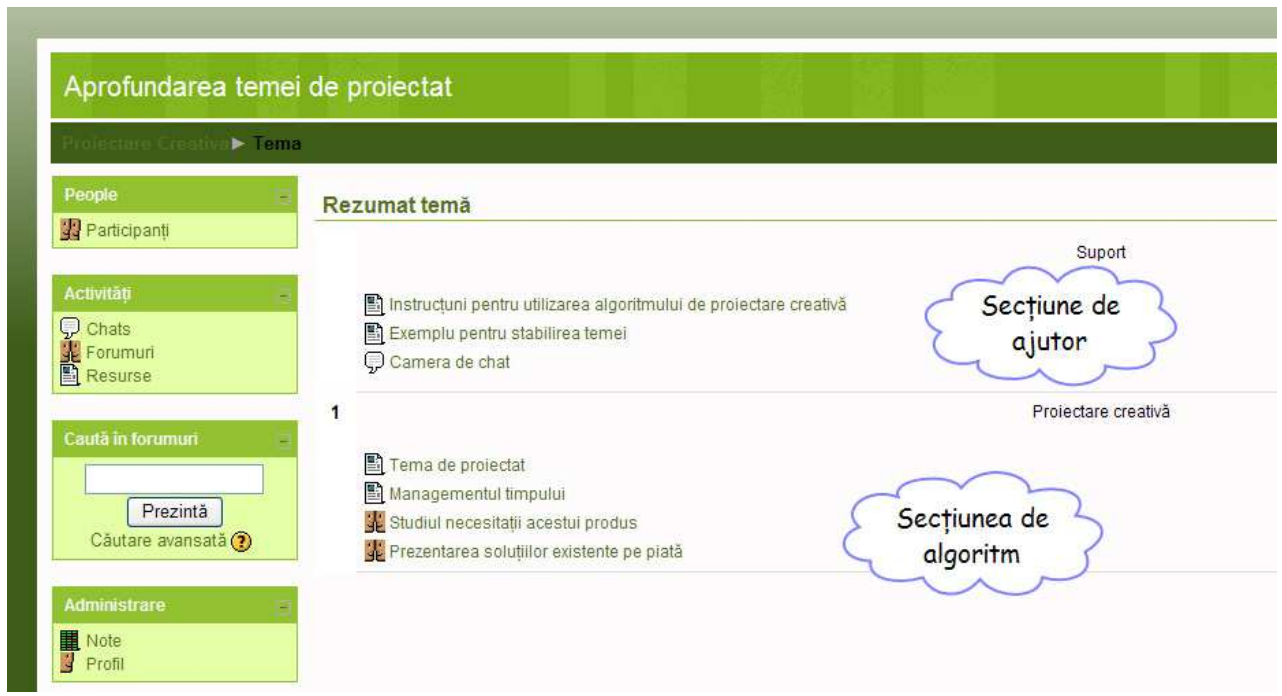

Fig. 5. E design - e research platform (problem definition, research planning, presentation of the up to date information)

\subsubsection{Determining the type of research that needs to be done}

After defining the precise research topic it is important to determine the types of research to be conducted. Each research concludes with a model. There are several types of models:

- Mathematical models (analytic). In this case a formal theory is developed, and the results of this theory can be compared against empirical values;

- Experimental models. These models require an experimental design observation of the phenomenon, data collection, data processing, and the validation of the model. There are three types of experimental research based on the level of understanding of the model:

- $\quad$ scientific models: The phenomenon is carefully observed and the model proposes a theory to explain it. Measurements and analyses will be carried out to validate the model;

- $\quad$ engineering models; Existing solutions are being studied, measurements are being undertaken and improvements of these solutions are proposed and implemented. These activities are repeated until no more optimisations are required;

- empirical models; In this case there is no need for a theory or an explanation for the phenomenon. The model works as a black box with inputs and outputs. Some experiments are usually performed, together with a statistical research, analysis and validation of the model.

Experimental investigations are run through a few steps, namely:

- Preliminary design of the experiment. The variables are selected, as well as their level of investigation. It is necessary to settle the parameters to be measured, their characteristics, measurement units, format, etc.; 
- Choice of the most suitable model for the desired outcome. The main experimental methods of research are: full factorial Experiment, fractional factorial Experiment, Latin Square, Taguchi Method;

- $\quad$ Conducting experiments and elaboration of the model;

- Verification of the model. A few questions are typically asked:

- The model reflects the system target in an acceptable way?

- For input data, does the simulation provide the correct output data?

- Are there statistical methods that allow the experimental verification of the model? The mostly used method is ANOVA.

To solve this issue, the chosen option was to build a representative model that describes all the manufacturing possibilities of the drilling heads. This model consists of an imaginary body with several steps, which can do several movements and has different adjustment possibilities. It also possesses several active edges, all with different shapes and positions.

Through customization, one can get different boring heads with various functions. The need of the representative tool is not only aimed towards a particular solution, but also towards synthesising the knowledge in this area and completing the network database.

\subsubsection{Research planning, use of project management methodology}

After the description of the problem and the choice of the research type that needs to be done are completed, the next step is the planning of research. This is performed by using the project management methodology. The most often used software in this field is Microsoft Project. The main stages of the planning process are shown in figure 6 .

Outside of research or optimization, a project can contain various modules for product design, design technology, prototype design and/or prototype technology design.

In order to make a realistic plan, it is very important to have a network database with complete information about: researchers, laboratories, knowledge in various fields, costs, resources available, etc.

\subsubsection{The research activity}

Proper implementation of the project must be made in accordance with the timetable of the project. Creativity in design research meetings (fig.7) may be carried out between research team members in a synchronous or asynchronous fashion. Experimental activities, the drawing up of a model and the design and manufacturing activities may be undertaken in one or more locations. The current software enables organising meetings with the participation of specialists located in different geographical areas (Beju \& Brindasu 2008).

Software products such as "Teamviewer" and "Teamcenter" enable that all participants of such a remote meeting make the viewing, the modifying and the completion of the drawings. The final version of the model (drawing) can be discussed by all of the participants and accepted by consensus or by vote. In order to develop new solutions, it is necessary to establish a virtual team. The methodology for choosing the team members is shown below in the pseudocode: 


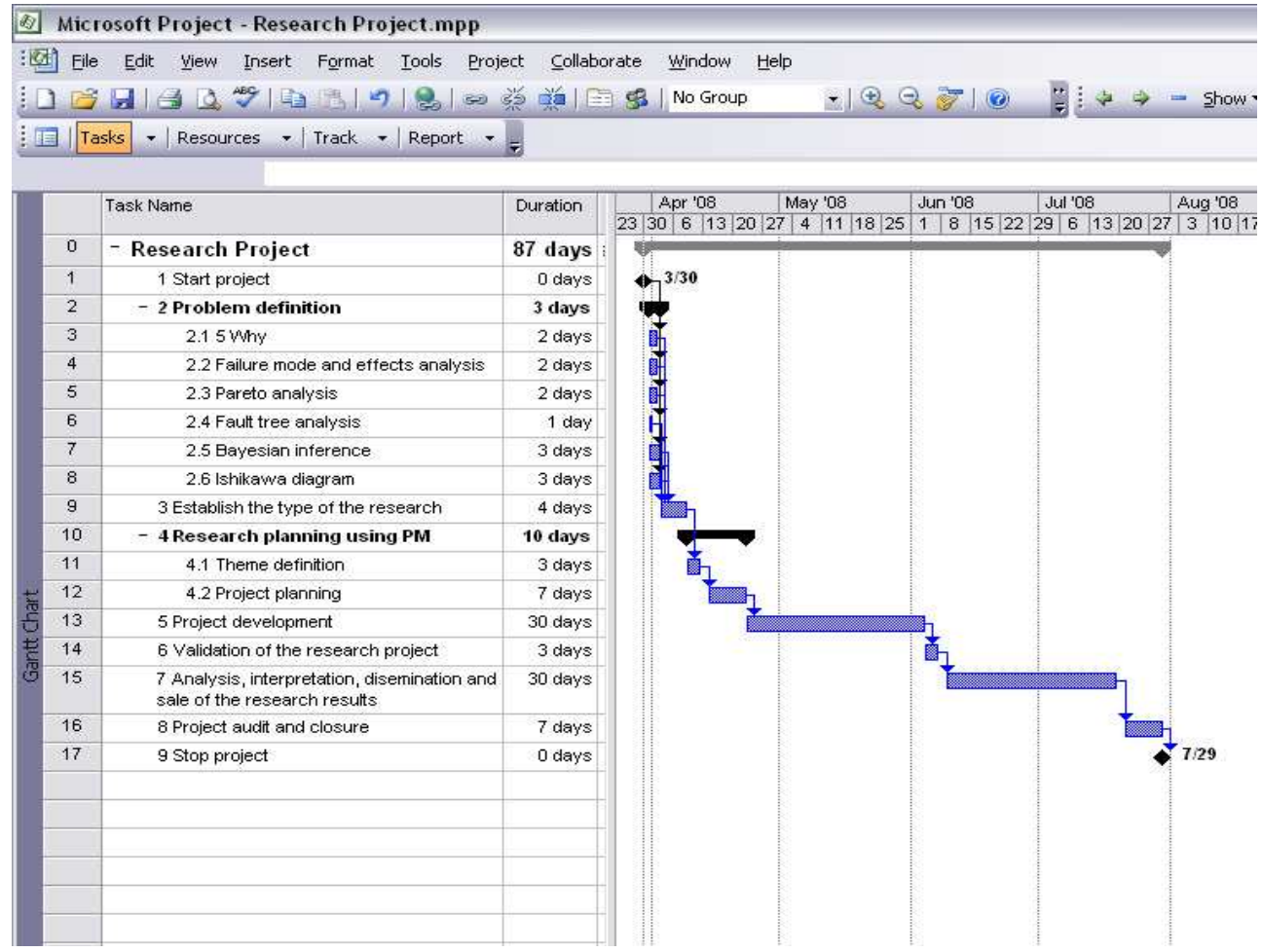

Fig. 6. Project planning

ESTABLISH the members of the virtual E-research Group;

DO WHILE the E-research group is complete

CONTACT a member of the virtual E-research group;

IF the person agrees to participate

THEN

EXPLAIN the working principles;

IF the level of knowledge must be checked (students)

THEN

The person solves a test;

IF the test results are good

THEN the person is accepted in group

ELSE select another person from the virtual group

END IF

ELSE

Accept the person in the group; END IF

END IF

END DO 
Research design sessions on the network can be done synchronously or asynchronously.

For the synchronous sessions, the stages can be:

- $\quad$ ESTABLISH working team members;

- INFORM research - design theme- to all group members by email;

- ORGANIZE a network meeting for establishing the analysis criteria. Each member will rate all the criteria. A specific software will determine the most important criteria as well as an indicator of their importance;

- ORGANIZE a networking session with the aim to develop new constructive solutions in connection with the proposed theme and in accordance with the criteria set out above - by using a creativity method;

- ORGANIZE a networking session with the aim of analyzing the existing constructive solutions based on the criteria set out above (consider all possible variants -the Morphological Method is very useful for this task);

- ORGANIZE a new session on the network (if necessary).

\section{Stabilirea Solutiei Constructive Optime}

\section{> Solutia Optima}

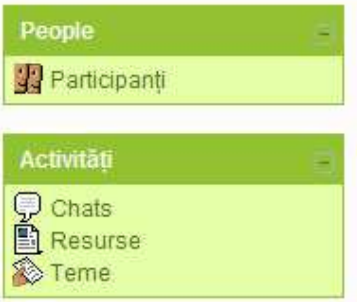

\section{Rezumat temă}

\section{Suport}

Vamera de chat

国 Exemplu pentru stabilirea solutiei constructive optime

\section{Proiectare creativă}

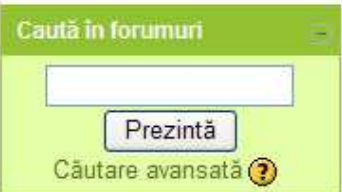

Faza V

国 Crearea matricei morfologice

Eliminarea combinatiilor imposibile din matricea morfologica

2 Eliminarea combinatillor neutilizabile din matricea morfologica

2. Solutille plauzibile

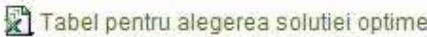

2 Stabilirea solutiei optime

圆 Solutia optima

Cursurile mele

Fig. 7. E-design - E-research platform (Creative design page) 


\begin{tabular}{|c|c|c|c|}
\hline \multicolumn{4}{|c|}{ Notele reprezinta: } \\
\hline Valoarea & Seminificatie & Valoarea & Semnificatie \\
\hline 0 & Nu este tolerabil & 8 & Solutie buna dar a lipsuri \\
\hline 1 & Insuficient & 7 & Solutie buna fara lipsuri \\
\hline 2 & Solutie dificila & 8 & Solutie fogrte buna \\
\hline 3 & Acceptabil & 9 & Mai mult decat presupus \\
\hline 4 & Satisfacator & 10 & Ideal \\
\hline 5 & Foarte satisfacator & & \\
\hline
\end{tabular}

Acordati note completand tabelul:

\begin{tabular}{|c|c|c|c|c|c|c|c|}
\hline \multirow{2}{*}{$\begin{array}{l}\text { Criteriul de analiza } \\
\text { Soluția constructivă }\end{array}$} & \multicolumn{2}{|c|}{$\begin{array}{c}\text { Uşurinta în } \\
\text { schimbarea } \\
\text { zonei active }\end{array}$} & \multicolumn{2}{|c|}{$\begin{array}{c}\text { Prețul total al } \\
\text { produsului }\end{array}$} & \multicolumn{2}{|c|}{ Fiabilitate } & \multirow[b]{2}{*}{$\begin{array}{l}\sum \text { Nota }^{*} \\
\text { Pondere }=\end{array}$} \\
\hline & Nota & $\begin{array}{c}\text { Nota* } \\
\text { Pondere }(0.45)\end{array}$ & Nots & $\begin{array}{c}\text { Nots* } \\
\text { Pondere }(0.33)\end{array}$ & Nota & $\begin{array}{c}\text { Nota* } \\
\text { Pondere }(0.22)\end{array}$ & \\
\hline T1P1M1 & 7 & 3.15 & 9 & 2.97 & 6 & 1.32 & 7.44 \\
\hline T2P1M1 & 7 & 3.15 & 9 & 2.97 & 7 & 1.54 & 7.66 \\
\hline T3P1IM1 & 7 & 3.15 & 9 & 2.97 & 6 & 1.32 & 7.44 \\
\hline T4P1M1 & 7 & 3.15 & 9 & 2.97 & 7 & 1.54 & 7.66 \\
\hline T5P1M1 & 7 & 3.15 & 8 & 2.64 & 7 & 1.54 & 7.33 \\
\hline T1P2M1 & 10 & 4.5 & 10 & 3.3 & 8 & 1.76 & 9.56 \\
\hline $\mathrm{T} 2 \mathrm{P} 2 \mathrm{M} 1$ & 10 & 4.5 & 10 & 3.3 & 9 & 1.98 & 9.78 \\
\hline T3P2M1 & 10 & 4.5 & 10 & 3.3 & 9 & 1.98 & 9.78 \\
\hline T4P2M1 & 10 & 4.5 & 10 & 3.3 & 10 & 2.2 & 10 \\
\hline
\end{tabular}

Fig. 8. E-design, E-research platform (page for establishing the best solution)

For asynchronous E-sessions, the problem definition, the research themes, as well as other necessary documents are sent to the team members, as showcased in the algorithm below:

- $\quad$ Each participant will receive a code (e.g. P1, P2, P3, P4, P5, P6);

- After the acknowledgement of the problem, each participant will write three proposals to solve the problems;

- The file is sent from one participant to the other in the order of their codes, until every participant has gotten hold of it

- Each participant fills in details, makes improvements, establishes details, makes comments on the previous ideas, until all the ideas are discussed by all the participants;

- One of the participants (usually the project manager) analyses, groups and compares the proposals (value analysis can be used, by marking each solution for all the proposed criteria and by all the team members);

- $\quad$ The project manager determines the best solution based on the marks awarded during the previous step

- A preliminary design of this very solution is performed;

- The chosen solution is analysed by all team members; 
- $\quad$ At the end, the chosen solution is optimised (fig.8). All attendees will once again award marks to the found solution. To adopt it, in general, five of the six team members must award the highest mark. Otherwise, the process starts again, until the best solution is obtained.

E-sessions can be organized in a classical manner or by using creative methods. The creative methods have the advantage of overcoming the psychological inertia. A number of methods can be used: consonance, extrapolation, combination, analogy, inversion, empathy, modifying, improving, INPUT-OUTPUT techniques, interrogative lists. These E-sessions are organized by topic, by the type of research, by the importance of the theme, by team skills, etc.

In the proposed case, a synchronous network meeting was organised, in order to build a representative model of boring tools. Some creativity methods were used. In order to break the psychological inertia of participants, questions were asked, such as:

- Imagine yourself in the place of the boring tool. How would you work easier?

- What material would you prefer being built of?

- From what part of you would you like cutting fluid to be provided?

- How would the edges better be placed?

- What happens if you look at the process from inside?....

The main purpose of the on-line creativity sessions was the representation of several modules with cylindrical or toroidal shapes. Based on these shapes, several inserts were placed on the cylindrical side and/or on the frontal side, in radial or tangent position.

After these steps, the final shape of the representative tool (fig.9) for hole manufacturing was obtained in asynchronous communication. The representative model (fig. 9) consists of several conical and cylindrical bodies placed on the same axis (the z-axis). The main form of the tool can be spindle or hole type. On the cylindrical, conical and frontal surfaces, inserts are placed in radial or tangent positions (Popescu et al., 2010).

Through customization, several real boring heads was obtained (fig.10).
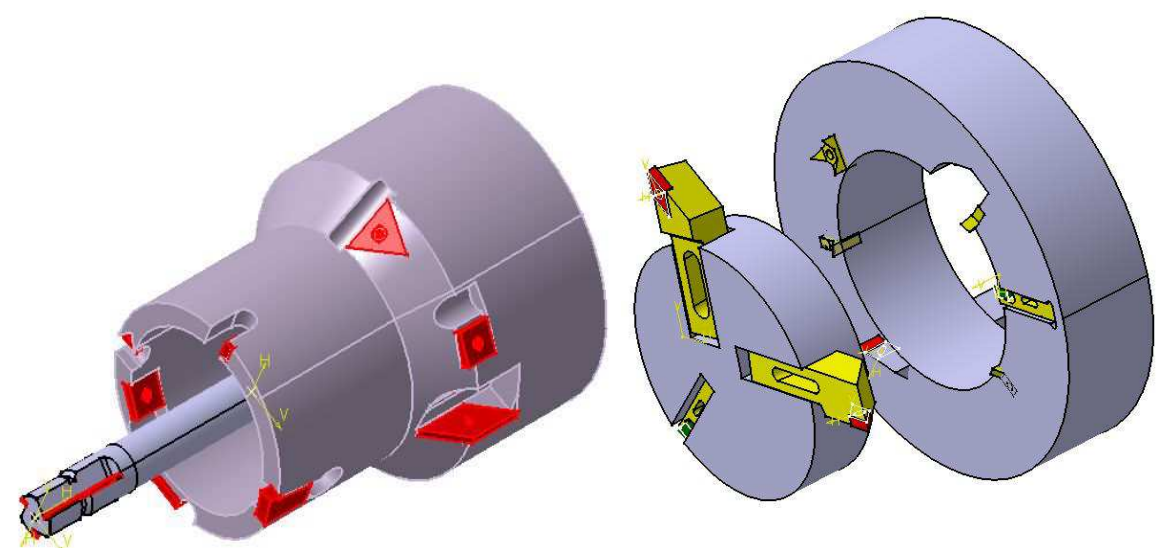

Fig. 9. Representative model of the boring tools 


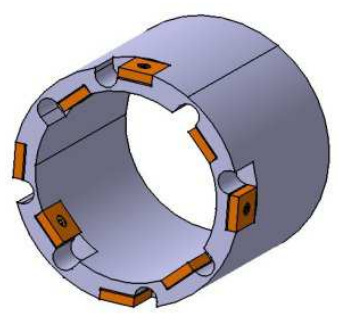

(a)

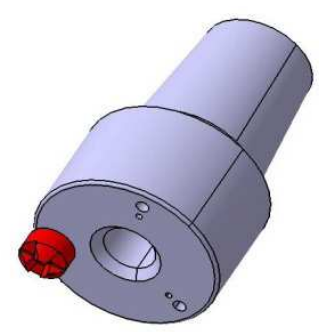

(d)

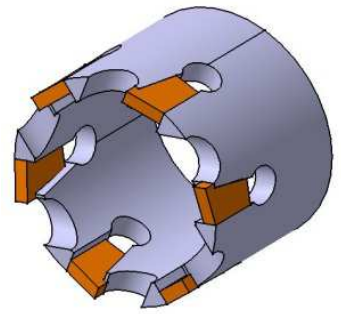

(b)

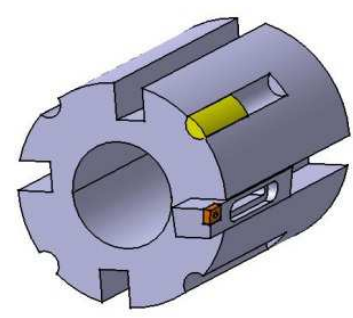

(e)

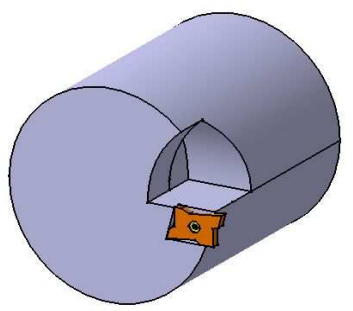

(c)

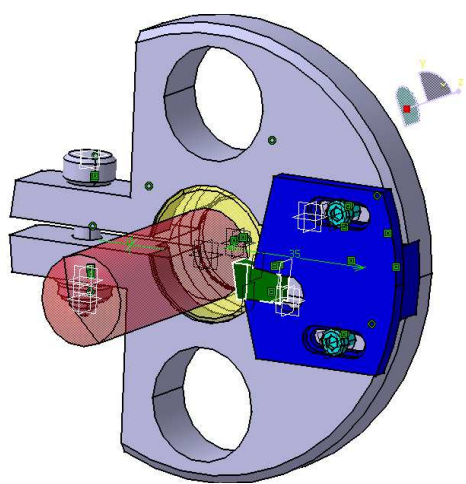

(f)

Fig. 10. Boring heads (a) with tangential inserts attached to the cylindrical part, (b) with inserts placed on the frontal side by the elasticity of the tool body, (c) with tangential insert placed on the frontal face, (d) with insert with several edges, (e) with tangential insert placed the cylindrical side of an adjustable body, (f) modular tool)

A more outstanding solution is a modular boring tool with a carbide helical drill or a drill with carbide inserts (in the case of larger diameter) and a special adjustable body for chamfer. The insert is fixed due to the elasticity of the tool body (fig. 10,f). This was the solution, which was finally chosen by the research team.

The following step represents the optimisation of the adopted solution.

Optimisation criteria were:

- $\quad$ small tension values, distributed as uniformly as possible;

- the type and form of the clamping system;

To this solution, there were several aspects that could be optimized: the shape of the insert, the clamping system and the tool body. Optimization began with the estimation of the forces. The study continued with a static (fig.11) and dynamic modelling process, and it finalised with a Finite Element Method analysis.

The clamping system due to the elasticity of the tool body is very economical in terms of space. It is necessary to precisely determine the shape of the elements, in order to obtain a 
secure and stable insert. The purpose of this phase of research was to determine the inclination of the insert and of the slot. Solving of the equation allowed the establishing of the optimal values $\theta_{1}=2 \ldots 15^{\circ}$ and $\theta_{2}=2 \ldots 6^{\circ}$.

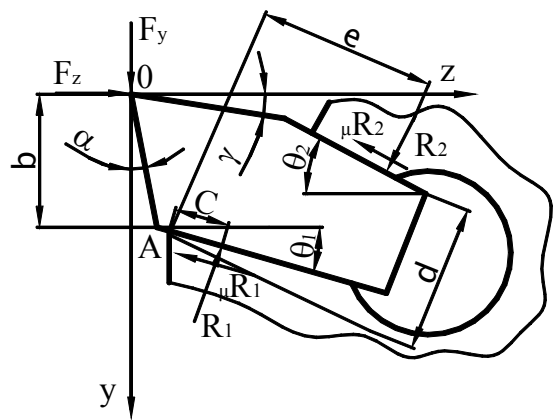

Fig. 11. Equilibrium analysis of the clamping system due to elasticity of the tool body

\subsubsection{Validation of the project results}

The result of the research project was discussed and validated by all the team members. Typically, other specialists and the beneficiaries are allowed to attend the synchronous meetings.

\subsubsection{Analysis, interpretation, dissemination and sale of research results}

The analysis of the results is performed on different processes, using the theoretical and experimental data. The results are graphics, tables and databases. These synthetic results can be presented in reports, research papers, databases, E-learning products etc.

\subsubsection{Audit of the research project}

The completion of the audit of the project is of great importance because it allows:

- to establish the manner in which the project was done;

- to ensure the satisfaction of the client;

- to track the flaws of the project during its development, as well as the causes of its success;

- to identify the changes that can improve it in the future.

Audit and project reports are tools of continuous improvement of the organization.

\subsubsection{Delivery of the research results to the beneficiary}

Accomplished research results should be delivered to the beneficiary in a useful manner.

\section{Conclusions}

Changes in the economic, social, political areas, as well as the availability of information determine changes in the needs and educational offers. One successful solution is E- 
learning. In order to respond to the dynamic needs of students, the E-learning educational systems must be modelled using the life cycle management and reference architectures. This paper presents an original model for reference architecture in the field of E-learning.

Among the most important activities that were highlighted by this reference architecture were the methodology for the realization of on-line courses and tutorials. These same activities are also the ones that raised the most important issues to the authors during their work. This paper presents the steps for elaborating an on-line course, as well as practical aspects that appeared in designing courses for mechanical engineering and cutting tools. The stages of developing a tutorial were also presented, alongside the main software products used in this field.

As for the issue of modern research and design, the team from Sibiu has redefined the notion of creative design, a process that uses creative methods in the Internet-based remote design process. Additionally, a model that describes the necessary stages of a remote research design activity was elaborated and an example of creative design carried out in the field of cutting tool was also presented.

The models presented in this paper correspond to the present-day information technology available. Future changes in technology will lead to changes in the hereby-presented technology.

\section{References}

Beju, L.D., Brindasu, P.D. (2008) Methodology For Organizing E-Creative Research And ECreative Design Sessions, Proceedings of the 19th International DAAAM Symposium, Pages: 83-84, ISSN 1726-9679, ISBN 978-3-901509-68-1, Editor Branko Katalinic, October 2008, Trnava, SLOVAKIA

Borza, S; Brindasu, P.D.; Beju, L.D. (2007) E-research centre and E creative design, new trends for $\mathrm{E}$ activities platform, Proceedings of The 6th WSEAS International Conference on E-Activities Pages: 86-93, December 2007, Puerto de la Cruz, SPAIN

Brîndaşu, P.D., Beju, L.D. (2007) E-creative Design for Cutting Tools Area, Annals of the MTeM for 2007 and Proceedings of the $8^{\text {th }}$ International Conference Modern Technologies in Manufacturing , ISBN 973-7937-07-04, Editor Cs Gyenge, October 2007, Cluj Napoca, Romania

Butz, M. (2006) Rule based evolutionary Online Learning System, Springer Verlag, ISBN 3540-25379-3, Berlin Heidelberg.

Creswell, J. (2009) Research Design. Qualitative, Quantitative and Mixed Method Approaches, Sage Publication, ISBN 978-1-4129-6556-9, London.

Kincheloe, J. (2006) Teachers as Researchers. Qualitative Inquiry as a Path to Empowerment, Routledge, Taylor \& Francis Group, ISBN 0-415-27645-4, London

Popescu, L.G., Brindasu, PD; Beju, LD (2010) The Strategic Analysis Model For A Flexible Virtual Research Centre, Proceedings of the 6th International Seminar on the Quality Management in Higher Education, vol I, Pages: 659-662, July 2010, Tulcea ROMANIA 


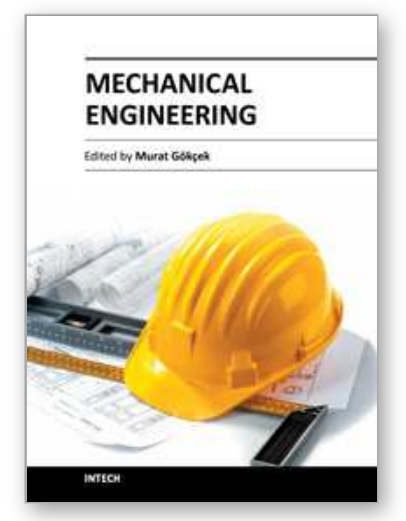

\author{
Mechanical Engineering \\ Edited by Dr. Murat Gokcek
}

ISBN 978-953-51-0505-3

Hard cover, 670 pages

Publisher InTech

Published online 11, April, 2012

Published in print edition April, 2012

The book substantially offers the latest progresses about the important topics of the "Mechanical Engineering" to readers. It includes twenty-eight excellent studies prepared using state-of-art methodologies by professional researchers from different countries. The sections in the book comprise of the following titles: power transmission system, manufacturing processes and system analysis, thermo-fluid systems, simulations and computer applications, and new approaches in mechanical engineering education and organization systems.

\title{
How to reference
}

In order to correctly reference this scholarly work, feel free to copy and paste the following:

Borza Sorin-loan, Brindasu Paul Dan and Beju Livia Dana (2012). Modern Methods of Education, Research and Design Used in Mechanical Engineering, Mechanical Engineering, Dr. Murat Gokcek (Ed.), ISBN: 978953-51-0505-3, InTech, Available from: http://www.intechopen.com/books/mechanical-engineering/modernmethods-of-education-research-and-design-used-in-mechanical-engineering

\section{INTECH}

open science | open minds

\author{
InTech Europe \\ University Campus STeP Ri \\ Slavka Krautzeka 83/A \\ 51000 Rijeka, Croatia \\ Phone: +385 (51) 770447 \\ Fax: +385 (51) 686166 \\ www.intechopen.com
}

\author{
InTech China \\ Unit 405, Office Block, Hotel Equatorial Shanghai \\ No.65, Yan An Road (West), Shanghai, 200040, China \\ 中国上海市延安西路65号上海国际贵都大饭店办公楼 405 单元 \\ Phone: +86-21-62489820 \\ Fax: $+86-21-62489821$
}


(C) 2012 The Author(s). Licensee IntechOpen. This is an open access article distributed under the terms of the Creative Commons Attribution 3.0 License, which permits unrestricted use, distribution, and reproduction in any medium, provided the original work is properly cited. 